\title{
OS SENTIDOS DO CUIDADO NO PARTO: UM ESTUDO INTERGERACIONAL
}

Natália Rejane Salim¹, Glauce Cristine Ferreira Soares ${ }^{1}$ Jacqueline Isaac Machado Brigagão², Dulce Maria Rosa Gualda ${ }^{3}$

RESUMO: Esta pesquisa de abordagem qualitativa teve por objetivo estudar os sentidos atribuídos ao cuidado no parto e analisar como as diferentes práticas de cuidado em Obstetrícia estão presentes no discurso de mulheres de diferentes gerações de uma mesma família. Foram realizadas entrevistas abertas que se desenvolveram como conversas o que tornou possível o compartilhar de histórias e sentidos. A análise privilegiou os mapas dialógicos, e possibilitou visualizar os sentidos que as mulheres atribuíram às diferentes práticas de cuidado que receberam e os efeitos destas práticas na experiência de cada uma. A análise das entrevistas possibilitou identificar duas categorias: Os sentidos do cuidado durante o parto e Os sentidos atribuídos à vivência da dor do parto. Os resultados mostram o compartilhar de repertórios, diferentes tipos de assistência ao parto e de contexto nas vivências, e seus efeitos nos significados atribuídos.

PALAVRAS-CHAVE: Parto normal; Discursos; Dor do parto; Assistência perinatal.

\section{THE MEANINGS OF CARE DURING CHILDBIRTH: AN INTERGENERATIONAL STUDY}

ABSTRACT: This research, with a qualitative approach, aimed to study the meanings attributed to care in childbirth and analyze how the different care practices in Obstetrics are present in the discourse of the women from different generations of the same family. Open interviews were undertaken which developed as conversations, making it possible to share histories and meanings. The analysis prioritized dialog maps, making it possible to visualize the meanings which the women attribute to the different care practices which they received, and the effect of these practices on each one's experience. The interviews' analysis made it possible to identify two categories: The meanings of the care during childbirth and The meanings attributed to the experience of the pain of childbirth. The results show the sharing of repertoires and different types of care during childbirth and of context of the experiences, and their effects on the meanings attributed.

KEYWORDS: Normal birth; Discourses; Pain of childbirth; Perinatal care.

\section{LOS SENTIDOS DEL CUIDADO EN EL PARTO: UN ESTUDIO INTERGENERACIONAL}

RESUMEN: Esta investigación de abordaje cualitativo tuvo como objetivo estudiar los sentidos asociados al cuidado en el parto y analizar cómo las diferentes prácticas de cuidado en Obstetricia se encuentran en el discurso de mujeres de diferentes generaciones de una misma familia. Fueron realizadas entrevistas abiertas que se desarrollaron como charlas, volviendo posible compartir historias y sentidos. El análisis privilegió los mapas dialógicos, lo que posibilitó visualizar los sentidos que las mujeres asociaron a las distintas prácticas de cuidado dadas a ellas y los efectos de estas prácticas en la experiencia de cada una. El análisis de las entrevistas propició identificar dos categorías: Los sentidos del cuidado durante el parto y Los sentidos asociados a la vivencia del dolor del parto. Los resultados muestran el compartir de repertorios, diferentes tipos de asistencia al parto y de contexto en las vivencias, y sus efectos en los significados asociados.

PALABRAS CLAVE: Parto; Discursos; Dolor del parto; Asistencia perinatal.

${ }^{1}$ Obstetriz. Doutoranda em Enfermagem pelo Programa Interunidade de Doutoramento da Escola de Enfermagem da Universidade de São Paulo - EE USP.

${ }^{2}$ Psicóloga. Doutora em Psicologia. Professora do Curso de Graduação em Obstetrícia da Escola de Artes Ciências e Humanidades da USP. ${ }^{3}$ Obstetriz. Livre docente. Professora do Departamento Materno Infantil e do Programa Interunidades de Doutoramento da EE USP. 


\section{INTRODUÇÃO}

Os modos de pensar a gravidez e o parto têm sofrido transformações no decorrer do tempo e nas diferentes culturas, assim como as práticas e os costumes que envolvem o processo do nascimento ${ }^{(1)}$. O cuidado em Obstetrícia tem se configurado de diferentes maneiras ao longo do tempo; a expressão mais antiga, a qual prevaleceu até o início do século XIX era o parto social. Este ocorria no contexto domiciliar e se caracterizava por ser um espaço feminino. A ajuda e o suporte espiritual eram oferecidos por mulheres da família, amigas e vizinhas, que haviam sido bem sucedidas em suas próprias experiências de parto. $\mathrm{O}$ nascimento marcava, significativamente, a vida das mulheres, e estava presente desde cedo em suas vidas até praticamente a morte ${ }^{(2)}$.

As parteiras desenvolviam seu trabalho numa perspectiva cultural e acompanhavam as mudanças atendendo as expectativas das mulheres que muitas vezes não eram as mesmas. Os historiadores não têm condições de precisar como o cuidado da parteira era prestado, pois não há dados. Parece que uma combinação de circunstâncias culturais, sociais e ambientais eliminava a necessidade de intervenções. Elas possuíam um saber e uma prática empírica para atuar em diversas situações ${ }^{(3)}$.

Autores que discutem a história da Obstetrícia demonstram que, a partir do século XIX, houve uma gradativa perda de espaço das parteiras, inicialmente para os cirurgiões barbeiros e mais tarde para os médicos, assim as mulheres foram perdendo o controle sobre o parto e o nascimento ${ }^{(4)}$. Deste modo, o modelo biomédico foi se consolidando e substituindo as práticas tradicionais no campo da Obstetrícia de maneira gradativa. À medida que as práticas foram sendo transformadas, as parturientes foram perdendo espaço e autonomia nas escolhas quanto ao tipo de parto, o lugar onde desejam parir e, principalmente, o controle sobre o próprio corpo no momento do nascimento, já que grande parte das práticas desenvolvidas dentro de um modelo biomédico são intervencionistas e prescrevem para as parturientes atitudes passivas. Pode-se ver assim a crise das práticas de saúde no modelo biomédico, apesar de todo o desenvolvimento científico e tecnológico, as práticas são limitadas diante das necessidades dos indivíduos e das populações ${ }^{(5)}$.

No entanto, desde o final da década de 1980, o movimento de humanização do parto tem buscado demonstrar que o parto cirúrgico, e grande parte das intervenções no momento do parto são desnecessárias; o movimento tem buscado garantir que as recomendações da Organização Mundial de Saúde, de 1996, sejam cumpridas. Ou seja, o incentivo ao parto vaginal, o aleitamento materno no pós-parto imediato, o alojamento conjunto, a presença de acompanhante escolhido pela mulher no processo de parto, a atuação de enfermeiras obstétricas e obstetrizes na atenção aos partos normais, e a inclusão de parteiras leigas no sistema de saúde nos lugares onde não há rede hospitalar ${ }^{(6)}$.

A gestação, o parto e o puerpério são períodos de transformações para uma mulher, nos quais ela necessita sentir-se cuidada pelos profissionais de saúde que a acompanham e pela rede de familiares e amigos. Vários aspectos da vida estão englobados nesta transformação e devem ser levados em conta, como a cultura, as crenças e os grupos dos quais a mulher participa, para que o cuidado possa ser realizado plenamente. Ou seja, respeitando-se as características individuais, as escolhas e a autonomia da mulher. Pesquisadores afirmam que o relacionamento da mulher com os profissionais da assistência é um dos fatores mais importantes que afetam diretamente a memória das mulheres e suas lembranças em relação ao parto e nascimento, o que tem grande importância para sua satisfação ${ }^{(7)}$.

Este estudo intergeracional teve como objetivo analisar o modo como as mulheres de diferentes gerações de uma mesma família atribuem sentido à experiência do parto e como as diferentes práticas de cuidado estiveram presentes nas trajetórias obstétricas destas mulheres. A família é uma instituição histórico-social que pode ser definida como um grupo que se constitui por pessoas unidas por vínculos de filiação e fraternidade, que tem características específicas, mas compartilha valores e crenças de outros grupos em um determinado tempo histórico ${ }^{(8)}$.

Na convivência intrafamiliar são compartilhados repertórios e práticas discursivas que moldam as relações e as configurações identitárias dos diferentes membros deste grupo. Ou seja, a família é um contexto privilegiado de troca de afetos e informações que possibilita o desenvolvimento de trajetórias singulares impregnadas de sentidos compartilhados. Dentro do contexto familiar os eventos relacionados com a maternidade, isto é, a gravidez, o parto e o pós-parto, possuem grande importância e vêm assumindo diferentes significados entre as gerações. Desta forma, torna-se importante conhecer e compreender os significados relacionados à vivência do parto e maternidade para mulheres de diferentes gerações pertencentes a uma 
mesma família. Além disso, o estudo evidencia as transformações nas práticas de cuidado ao longo do tempo e sua influência na experiência dessas mulheres.

\section{MÉTODO}

Trata-se de uma pesquisa qualitativa que privilegiou os microprocessos de produção de sentidos, assim conceituado:

O sentido é uma construção social, um empreendimento coletivo mais precisamente interativo, por meio do qual as pessoas, na dinâmica das relações sociais, historicamente datadas e culturalmente localizadas, constroem os termos a partir dos quais compreendem e lidam com as situações e fenômenos a sua volta ${ }^{(9: 34)}$.

O método de coleta de dados escolhido foi a entrevista aberta, pois possibilita o estabelecimento de um diálogo entre pesquisador e participantes. Considerou-se que a entrevista permite a construção de um espaço envolto por empatia, sensibilidade, humor e sinceridade, sentimentos que são fundamentais na relação com o outro ${ }^{(10)}$.

Foram entrevistadas cinco mulheres da mesma família, sendo uma da primeira geração: Sarah (87 anos), a matriarca; três da segunda geração: Débora (68 anos), Elizabeth (60 anos), Cristina (47 anos); e uma da terceira geração: Alice (35 anos). A noção de geração utilizada está associada aos papeis sociais assumidos dentro da família: primeira geração - avó, segunda geração filhas e terceira geração neta. A avó teve filhos no período 1945 a 1970, as filhas no período 1980 a 2002 e a neta em 1997. O primeiro contato ocorreu com a matriarca da família, moradora de um bairro pobre da zona sul de São Paulo. Durante este contato ela nos contou a respeito das filhas e neta e nos forneceu o telefone destas. As entrevistas foram agendadas conforme desejo e disponibilidade de cada participante. A realização destas ocorreu no domicílio das mulheres, tiveram duração média de 60 minutos e foram gravadas. Todas as entrevistadas assinaram o termo de consentimento informado e concordaram com a gravação das entrevistas. A entrevista foi iniciada com a frase: 'Me conte um pouco sobre a sua história e como foi o nascimento de seus filhos'. O período da coleta de dados foi de março à maio de 2011.

As entrevistas, primeiramente, foram transcritas. Após esta fase foi feita a análise que se iniciou com a construção dos mapas dialógicos.

Os mapas são instrumentos de visualização do processo de interanimação que possibilitam, entre outras coisas, mostrar o que acontece quando perguntamos certas coisas ou fazemos certos comentários ${ }^{(9: 38)}$.

Os relatos de cada uma das entrevistadas foram mapeados. A análise das entrevistas focalizou os discursos e os repertórios interpretativos compartilhados acerca dos cuidados recebidos durante a gravidez e o parto e da dor no momento do parto. Os repertórios interpretativos são um conjunto de palavras e expressões que são frequentemente organizados em torno de uma, ou mais, metáforas. Esses historicamente construídos e compartilhados compõem o senso comum de uma determinada sociedade, apesar de que alguns podem estar restritos a grupos específicos ${ }^{(11)}$.

O projeto de pesquisa foi aprovado pelo Comitê de Ética em Pesquisa (CEP) da Escola de Enfermagem da Universidade de São Paulo, respeitadas as exigências da Resolução 196/1996, do Conselho Nacional de Saúde.

\section{RESULTADOS}

Os resultados da análise das entrevistas foram organizados em duas dimensões: Sentidos do cuidado durante o parto e Sentidos atribuídos a vivencia da dor.

\section{Sentidos do Cuidado Durante o Parto}

A análise das entrevistas possibilitou identificar que as entrevistadas observaram diferenças significativas nos modos como o cuidado foi realizado em diferentes instituições e por diferentes profissionais. Nos relatos, dois aspectos do cuidado foram destacados pelas participantes: a importância de uma relação de afeto e confiança com os/as profissionais responsáveis pelo cuidado à saúde no momento do parto; a sensação de desrespeito e abandono que algumas sentiram no momento do parto.

\section{Relação de confiança e afeto}

Para as mulheres das três gerações é fundamental que haja uma relação de confiança e afeto com os profissionais que realizam a assistência no momento do parto, como relato a seguir:

[...] quando a parteira chegou já tinha nascido fazia 20 minutos, ai ela só fez o parto da placenta, ficou tudo bem, lavou o bebê, cuidou de mim 5 dias e foi tudo bem, tudo normal [...] a Vivian nasceu em casa de bumbum prá fora, em vez da cabeça o bumbum. Foi

Cogitare Enferm. 2012 Out/Dez; 17(4):628-34 
um parto dificil, mas nasceu, demorou mais porque veio de bumbum, esse foi o que mais demorou, mas a parteira era muito boa, parteira diplomada mesmo ela fazia todo parto da mulherada, era muito boa. (Sarah, $1^{\text {a }}$ geração)

No relato abaixo, Marina conta a sua experiência dentro do ambiente hospitalar e a participação do seu marido e do médico. Fica claro o quanto ela valorizou a relação estabelecida com o médico:

O médico foi se arrumar com o meu marido, quando ele voltou foi quase de 15 minutos a Bianca já estava nascendo. Veio aquela força e não deu tempo, não levei anestesia e ele já me deu a Bianca. Eu falei: 'é isso que é benção'. A Bianca nasceu às sete horas em ponto, tava um dia maravilhoso, o sol batendo bem na janela, aquele raio batendo bem na minha barriga. Chorei de emoção, meu marido chorou, e até meu médico chorou. Ele batia palma para mim! (Marina, $2^{\mathrm{a}}$ geração)

Para Débora, a relação com o profissional que assiste a seus partos é fundamental, ela se recorda do nascimento do seu outro filho como sendo muito bom:

[...] foi um parto maravilhoso, normal, um médico que até hoje eu nunca mais esqueci a fisionomia dele, e foi assim um parto muito legal. As coisas ruins marcam, mas as boas marcam também. (Débora, $2^{\mathrm{a}}$ geração)

\section{O desrespeito e abandono}

Nas entrevistas as mulheres da segunda e terceira geração relataram situações em que se sentiram desrespeitadas e não tiveram os seus desejos respeitados pelos profissionais de saúde.

[...] quando a bolsa rompeu eram duas e meia da manhã. Fiquei o dia inteiro com dor. As enfermeiras nem falavam comigo, me deixaram sozinha efalaram que era frescura minha. Eu falei que ia vomitar, elas não fizeram nada e eu tive que vomitar no chão. (Cristina, $2^{\mathrm{a}}$ geração)

Marina nos conta sobre a sua revolta em ter sido anestesiada no momento do nascimento de sua segunda filha:

O filho da mãe me deu anestesia peridural, ele levantou a cama de novo porque eu falei que queria tudo igual da Bianca. Mas aí, eu fiquei brigando com ele [...] eu falava: 'porque você me anestesiou? Quem mandou você me anestesiar?!' [...] Eu só fiquei brava porque ele me deu anestesia e eu não queria, porque ia ser igualzinho da Bianca. (Marina, 2a geração)

Débora se queixa da posição em que foi colocada no momento do parto durante o nascimento de seu segundo filho:

[...] só foi uma posição muito difícil prá mim, do jeito que eles me colocaram na mesa de parto. Foi uma posição terrivel, eu parecia uma vaca pendurada, pegaram meu calcanhar e penduraram lá em cima. Foi a posição que eles acharam adequada, mas prá mim não foi. Eu fiquei traumatizada, eu tive partos normais, foi um diferente do outro, mas esse foi terrivel. Essas coisas marcam, a gente não esquece, não esquece das coisas boas, mas também das coisas ruins, marcam. (Débora, $2^{\mathrm{a}}$ geração)

Para Alice foi difícil lidar com a falta de atenção do médico:

O médico ia lá só para fazer o toque e ver a dilatação, passava nas mulheres que tavam lá, olhava o papel, não me deu atenção, fazia o toque e ia embora. Tanto é que ele nasceu na sala de pré-parto se não fosse uma moça lá chamar o médico. Saiu a cabeça e não saiu o corpo ai eu falei 'moça chama o médico prá mim'. Ai ela foi lá com aquele barrigão. (Alice, $3^{\mathrm{a}}$ geração)

Elizabeth contou como se sentiu sozinha durante o trabalho de parto:

Foi dificil prá mim porque eu fiquei sozinha e estava com muita dor, foi parto induzido, foi dificil [...]. Me senti muito sozinha! (Elizabeth, 2a geração)

\section{Os sentidos atribuídos à vivência da dor do parto}

Os repertórios interpretativos sobre a dor aparecem de dois modos nos discursos: a dor como necessária e fundamental para o processo de parto; a dor como contraponto à alegria e prazer sentido no nascimento dos/as filhos/as.

\section{A dor necessária}

A dor aparece explicitamente no discurso da participante da primeira geração como sendo parte do processo de parir e necessária para que o parto se 
efetive. Na mesma perspectiva, uma das participantes da segunda geração relata que a ausência da dor nos momentos que antecedeu o parto lhe causava preocupação de que houvesse algo errado:

Ai veio aquela dor de ter, a parteira ajudava, esperava a dor necessária, depois nascia. (Sarah, $1^{\mathrm{a}}$ geração)

Fui lá pro quarto, as mulheres tudo gritando e uivando [...] tinh a uma que ficou toda sem se mexer, eu ia lá e fazia massagem nelas [...]. Eu pensei que tinha alguma coisa esquisita comigo porque eu não sentia nada! Fui prá uma janela e pensei, 'meu Deus, o que está acontecendo comigo que eu não sinto dor?' (Marina, $2^{\mathrm{a}}$ geração)

\section{A dor que antecede a alegria}

A análise permitiu identificar que a dor aparece na mesma oração que a alegria, e que o sentido atribuído à dor foi o de possibilitar o nascimento e a alegria advinda deste:

Foi uma dor tremenda e ai ela finalmente nasceu! Chorei de alegria, parto normal, e acabou imediatamente aquela dor e eu chorei de alegria, de felicidade. Foi assim o meu primeiro parto. (Débora, $2^{\mathrm{a}}$ geração)

Minha mãe me levou, mas não pôde ficar para assistir o parto. Eu não senti medo, mas a dor era muita [...]. Uma dor insuportável que os vidros do quarto era tudo pintado, não dava para ver se era dia, aí eu vi uma parte descascada e vi que já era de noite e eu tinha entrado lá quando era dia. Depois, foi só alegria, depois que nasceu eu não senti nada foram me levar pro quarto e eu já fui andando. (Alice, $3^{\mathrm{a}}$ geração)

Depois de toda aquela dor foi uma benção poder pegar aquela criatura nos meus braços e saber que era minha filha. (Elizabeth, $2^{a}$ geração)

\section{DISCUSSÃO}

Os discursos das participantes da pesquisa se referem a sentidos compartilhados acerca da maternidade, parto e cuidado que são produzidos nas interfaces entre conversas, vivências concretas das experiências de parto e a cultura que possibilitam a produção de sentidos para as experiências individuais de cada uma delas.
O que se observou na análise das entrevistas foi que houve variação na forma de vivenciar o parto em diferentes circunstâncias. Este fato já tem sido amplamente constado nas Ciências Humanas. Afirma-se que os sistemas de nascimento estão dentro de um sistema cultural mais amplo, onde sua posição está articulada com a via política, econômica e de socialização dos que participam do parto juntamente com a localização dos conceitos dentro da abrangência do sistema ideológico. A autora constatou que as diversas culturas desenvolveram maneiras específicas de conduzir o parto; verificou que existem diferenças significativas no que se referem às características biossociais, tais como conceituação, natureza do processo de tomada de decisão, e sistemas de assistência e suporte disponíveis para a parturiente ${ }^{(12)}$.

A análise das entrevistas possibilitou a visualização das diferentes práticas de cuidado prestadas a essas mulheres e os efeitos destas práticas nas experiências. Sarah nos conta de suas vivências com a parteira, ela nos conta que tinha muita confiança na competência da parteira e que mesmo em situações difíceis a competência da parteira foi muito útil. Marina nos conta como se sentiu empoderada no nascimento de Bianca e o quanto foi importante o fato do médico aplaudí-la. A relação de confiança que se estabelece com os/as profissionais de saúde durante o parto está intimamente associada à capacidade de empatia dos profissionais. Ou seja, na medida em que o profissional é capaz de se colocar no lugar da mulher e da família, passa a reconhecer a importância desse momento ${ }^{(13)}$.

Nos relatos da segunda geração fica evidente que nem sempre a hospitalização resulta em um cuidado efetivo. Cristina em seu relato evidencia a sensação de abandono e de desrespeito que sentiu durante o período que antecedeu o parto, já que as profissionais do hospital não acreditavam nas queixas de dor. Marina relata sua revolta por não ter sido ouvida e respeitada quanto ao seu direito de escolha de não ser anestesiada. Débora se queixa da posição que foi colocada durante o parto e Elizabeth relata o abandono.

Fica evidente nos relatos que muitas vezes no processo de hospitalização do parto a autonomia e os desejos da mulher são colocados em segundo plano. Ou seja, as regras institucionalizadas atuam como barreira em relação à vontade da mulher, ao seu poder de escolha e desejos. Os saberes subjetivos das parturientes em relação ao seu próprio corpo, são ignorados e negados violentamente; são substituídos pelos saberes dos profissionais e pelas tecnologias que estes usam como garantia de $\mathrm{vida}^{(14)}$. 
As evidências científicas mostram que ações intervencionistas realizadas durante o parto não mostram eficácia e resultados concretos. Contudo, continuam a ser utilizados sem explicação, sem o consentimento e esclarecimento para a parturiente, o que gera uma relação verticalizada entre o profissional e a mulher, sem negociação e, acima de tudo, sem relacionamento, culminando em desrespeito ${ }^{(15)}$. Vale ressaltar que para uma mesma mulher há diferenças entre os partos e que essa é atribuída, especialmente, ao profissional responsável pelo parto e à relação que esse estabelece com a mulher. É o caso de Marina e Débora que sentiram diferença entre o parto da primeira filha e o da segunda, resultado da relação com o profissional.

Embora a dor durante o trabalho de parto esteja associada às contrações uterinas e seja uma resposta fisiológica, a forma com que cada mulher lida e percebe a dor se dá como um processo subjetivo e complexo. A natureza da dor tem características tanto fisiológicas como psicológicas ${ }^{(16)}$. O medo do desconhecido está associado ao aumento da ansiedade e da sensação da dor, por este motivo quando a mulher recebe informações previamente a respeito do parto isso reflete em autoconfiança e sentimentos positivos durante o processo $^{(13)}$. Algumas mulheres deste estudo relataram a dor como parte inerente do processo de nascimento, como Sarah que conceitua a dor como 'a dor de ter o bebê'. Outras participantes apontaram a intensidade da dor do parto com a alegria do nascimento, o que se torna mais importante e relevante que a dor vivenciada. Entretanto, podemos relacionar a dor também as condições ambientais e ao tratamento e cuidado que as mulheres recebem durante o parto. Desta forma, conhecer as necessidades de cuidado das mulheres durante o processo do nascimento é papel fundamental da equipe de saúde que atua diretamente na assistência obstétrica.

\section{CONSIDERAÇÕES FINAIS}

As diferentes vivências de parturição de mulheres de uma mesma família nos mostram o compartilhar de repertórios e os diferentes tipos de assistência nas gerações. Conhecer as histórias de parturição e as singularidades que estão envolvidas nessas histórias nos permite entender os valores que ligados à vivência do parto e nascimento.

Por meio deste estudo foi possível ver mudanças associadas com a assistência obstétrica quanto ao tipo de profissional que atua diretamente ao cuidado das mulheres durante o parto, o contexto que se dá o nascimento e os significados atribuídos à dor do parto. Reconhecer a importância do cuidado para as mulheres durante a atenção ao parto torna-se de grande importância à medida que as práticas profissionais na assistência obstétrica devem ir ao encontro das necessidades individuais das mulheres, com respeito e sensibilidade, desta forma mais pesquisas devem ser feitas nesta perspectiva.

\section{REFERÊNCIA}

1. Mott ML. As parteiras e a assistência ao parto em São Paulo nas primeiras décadas do século XX. Rev Inst Hist Geogr Bras. 2002;163(415):67-84.

2. Davis-Floyd R. Birth as a rite of passage. In: Birth as an American Rite of Passage. California: University of California Press 1992. p. 1-21.

3. Romalis S. Childbirth: alternatives to medical control. Texas: University of Texas Press; 1981.

4. Spink MJP. As origens históricas da obstetrícia moderna In: Psicologia social e saúde: práticas, saberes e sentidos. Petrópolis: Vozes 2003. p. 169-93.

5. Ayres JRCM. Care and reconstruction in healthcare practices. Interface - Comunic., Saude, Educ. [Internet] 2004,8(14):73-92. [acesso em 23 set 2012] Disponível: http://scielo.br/scielo.php?=script_arttext\&pid=S1414$32832004000100005 \& \operatorname{lng}=$ eng\&nrm=iso

6. Organização Mundial da Saúde. Maternidade segura. Assistência ao parto normal: um guia prático. Genebra: OMS; 1996.

7. Domingues RMSM, Santos EM, Leal MC. Aspectos da satisfação das mulheres com a assistência ao parto: contribuição para o debate. Cad. Saúde Pública [Internet] 2004;20(Suppl 1) [acesso em 23 set 2012] Disponível: http://scielosp.org/pdf/csp/v20s1/06.pdf

8. Correa OBR. O legado familiar: a tecelagem grupal da transmissão psíquica. Rio de Janeiro: Contra Capa; 2000.

9. Spink MJ. Linguagem e produção de sentidos no cotidiano. Rio de Janeiro: Biblioteca Virtual de Ciências Humanas do Centro Edelstein de Pesquisas Sociais; 2010.

10. Rubin HJ, Rubin IS. Qualitative interviewing: the art of hearing data. California: Sage; 2005.

11. Potter J. Discourse analysis and constructionist 
approaches available. In: Richardson JTE, editor. Handbook of qualitative research methods for psychology and the social sciences. Leicester: BPS Books; 1996. p. 125-140.

12. Jordan B. Birth in four cultures. USA: prospect heights. 4th ed. Illinois: Waveland; 1993.

13. Lopes CV, Meincke SMK, Carraro TE, Soares MC, Reis SP, Heck RM. Experiências vivenciadas pela mulher no momento do parto e nascimento de seu filho. Cogitare enferm. [Internet] 2009;14(3) [acesso em 10 ago 2012]. Disponível: http://ojs.c3sl.ufpr.br/ojs2/index. php/cogitare/article/view/16178/10697

14. Pereira, WR. Poder, violência e dominação simbólicos nos serviços públicos de saúde que atendem à mulheres em situação de gestação, parto e puerpério [tese]. Ribeirão Preto (SP): Universidade de São Paulo; 2000.

15. Tornquist, CS. Paradoxos da humanização em uma maternidade no Brasil. Cad. Saúde Pública. [Internet] 2003,19(Suppl. 2) [acesso em 19 mar 2012]. Disponível: http://www.scielo.br/pdf/csp/v19s2/a23v19s2.pdf

16. Lowe KN. The nature of labor pain. Am j. obstet. gynecol. [Internet] 2002;186(5) [acesso em 24 jul.2012]. Disponível: http://www.ajog.org/article/S00029378(02)70179-8/abstract 